\title{
Common names and proper nouns: Morphosyntactic evidence of a complete nominal paradigm
}

\section{Samuel Jambrović*}

\begin{abstract}
The terms "common noun" and "proper name" encode two dichotomies that are often conflated. This paper explores the possibility of the other combinations-"common name" and "proper noun"-and concludes that both exist on the basis of their morphosyntactic behavior. In support of common names, inflectional regularization is determined to result from a "name" layer in the structure, meaning that common nouns that regularize are, in fact, common names (computer mouses, tailor's gooses). In support of proper nouns, there are bare singular count nouns in English that receive definite interpretations and seem to be licensed as arguments by the same null determiner as proper names (I left town, she works at $\underline{\text { home }}$. . Not only does a four-way distinction between nouns, names, proper nouns, and proper names achieve greater empirical coverage, but it also captures the independent morphosyntactic effects of [PROPER] and [NAME] as features on D and N, respectively.
\end{abstract}

Keywords. proper names, bare nouns; allomorphy; regularization; determiners; reference; compounds; roots

1. Introduction. It has long been observed that proper names and common nouns have different inflectional behavior. ${ }^{1}$
a. $\quad$ child $\rightarrow$ children
b. Child $\rightarrow$ Childs

If Child the name is derived from child the noun, the shared root cannot be the source of the regularization in (1b). The terms "common noun" and "proper name" suggest that these nominal elements differ along two dimensions- "common" versus "proper" and "noun" versus "name"- which are often collapsed into a single contrast. In doing so, research on proper names and bare arguments has overlooked key generalizations.

The data in (1) are only part of the story, however. At a descriptive level, there is not always a consistent definition of proper names. For example, many speakers would include the character names in (2), but these require a determiner as singular forms and do not regularize as plural forms.
a. $\quad$ the Big Bad Wolf $\rightarrow$ Big Bad Wolves/*Wolfs
b. the Golden Goose $\rightarrow$ Golden Geese/*Gooses

Even a distributional account of proper names, such as "names that appear as bare arguments", fails to identify a set with uniform inflectional behavior. Surnames always regularize (3), but character names display variable inflection (4).

\footnotetext{
* I am immensely grateful to María Cristina Cuervo and Diane Massam for their continued support of this work. Moreover, I would like to thank the members of the University of Toronto's Syntax Project as well as Neil Banerjee and Keith Tse for their insightful questions during the LSA Annual Meeting. Author: Samuel Jambrović, University of Toronto (samuel.jambrovic@utoronto.ca).

${ }^{1}$ For reasons of space, I primarily use English data, but these phenomena are not limited to English. See section 3.1 for similar data in German and Hungarian.
} 
(3) $\quad$ a. Freeman $\rightarrow$ Freemans/*Freemen

b. Proudfoot $\rightarrow$ Proudfoots/*Proudfeet

c. Wolf $\rightarrow$ Wolfs $/ *$ Wolves

(4) a. Mickey Mouse $\rightarrow$ Mickey Mice/Mouses

b. Gandy Goose $\rightarrow$ Gandy Geese/Gooses

c. Wonder Woman $\rightarrow$ Wonder Women/Womans

A further issue with the bare argument definition of proper names is that, along with the Big Bad Wolf and the Golden Goose, it rules out the Bronx and the Hague, which appear to be "true" names that happen to include a determiner. Lastly, there are cases of bare singular count nouns, such as those in (5), that denote unique referents and yet are not names.

(5) a. Diana left town in a hurry.

b. She found them asleep in bed.

Taken together, the data in (1)-(5) raise questions at all levels of the noun phrase: features, projections, and structural configurations.

By examining the common-proper and noun-name dichotomies separately, this paper makes an important discovery: not only are "proper" and "name" distinct notions, but they also have independent morphosyntactic effects. First, inflectional regularization can be linked exclusively to a "name" layer in the structure, not a "proper" one; there are common names in addition to proper names, and both regularize in plural contexts. Second, the proper determiner is not limited to selecting names. Proper nouns - the combination of a proper determiner and a common noun-are legitimate syntactic configurations and, like proper names, receive a definite interpretation as bare arguments.

The remainder of this paper is structured as follows. In section 2, I present Ghomeshi \& Massam's (2009) dual-feature approach to proper names and explore the full implications of this system. In section 3, I focus on the first of these features, [NAME] and argue that its morphosyntactic effects identify the existence of common names. In section 4, I investigate the second feature, [PROPER], and show that it is compatible with common nouns as well as names. Finally, in section 5, I summarize the major findings related to each feature.

2. Theoretical background. Assuming that "proper" and "name" encode different contrasts, the question is how to capture each one structurally. That is, at what point in the derivation does a root become a noun or a name, and at what point does this noun or name become a "proper" one? Many authors identify an initial division at the N-level (Adger 2003; Camacho 2019; De Clercq 2008; Ghomeshi \& Massam 2009; Longobardi 2005; Matushansky 2006; Thomsen 1997). ${ }^{2}$ Far fewer consider "proper" separately from "name" since their arguments do not rely on a more nuanced distinction. As Ghomeshi \& Massam's (2009) comprehensive analysis reveals, however, two features are minimally required to differentiate the distribution of proper names from that of singular count nouns: a [NAME] feature on $\mathrm{N}$ and a [PROPER] feature on D. I will briefly review the motivation for these features before elaborating on them in sections 3 and 4.

\footnotetext{
${ }^{2}$ Nevertheless, there are differences in these accounts. Adger (2003), De Clercq (2008), and Ghomeshi \& Massam (2009) use features, while Camacho (2019), Longobardi (2005), Matushansky (2006), and Thomsen (1997) distinguish names from nouns from a semantic perspective.
} 
The evidence for a [NAME] feature on $\mathrm{N}$ is found in languages like Modern Greek and Seri, where proper names typically appear with an overt determiner yet are still interpreted as names in determinerless constructions. In other words, [NAME] cannot be a feature on D, leaving $\mathrm{N}$ as the only alternative.

The evidence for a [PROPER] feature on D is found in languages like English and Spanish, where proper names occur as bare arguments (Diana ran), unlike singular count nouns (*woman ran). If Diana and woman are both singular and definite, the null determiner can only be explained by an additional feature on $\mathrm{D}$.

Based on these facts, Ghomeshi \& Massam (2009: 76) propose the following structure for proper names.

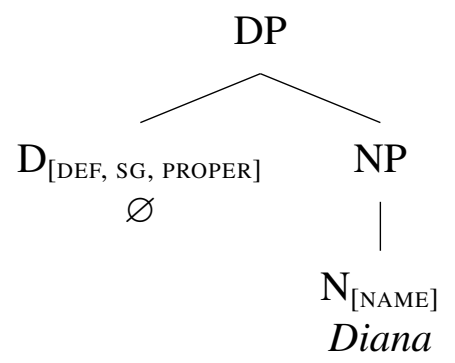

Furthermore, as illustrated in Table 1, this dual-feature system generates four combinatorial possibilities.

\begin{tabular}{lcc} 
& $\mathrm{N}$ & $\mathrm{N}_{\text {[NAME] }}$ \\
\hline $\mathrm{D}$ & common noun & common name \\
& the woman & the Diana $($ I know $)$ \\
$\mathrm{D}_{\text {[DEF, SG, PROPER }]}$ & proper noun & proper name \\
& $?$ & Diana \\
\hline
\end{tabular}

Table 1. Typology of nouns and names

For more examples of common names, see the discussion in section 3.3. As for the configuration labeled "proper noun", Ghomeshi \& Massam (2009: 83) rule out this possibility "since the selection properties of the proper determiner would not be satisfied", there are definite usages of bare singular count nouns in 4.3 that challenge this claim.

First, I concentrate on the feature [NAME] and the morphosyntactic effects that can be isolated from the presence or absence of [PROPER], including the regularization that is observed with common names.

3. A theory of [NAME]. It remains an open question whether names belong to their own syntactic category. Anderson (2007), Kim et al. (1994), Marcus et al. (1995), and Pinker (1998, 1999) argue that they do, while Borer (2005), Camacho (2019), De Clercq (2008), Longobardi (1994, 2005), Matushansky (2006), and Thomsen (1997) label names as NPs. A feature-based approach seems amenable to both perspectives, distinguishing nouns $(\mathrm{N})$ from names $\left(\mathrm{N}_{[\mathrm{NAME}]}\right)$ without resorting to a novel lexical projection (NameP).

There is both syntactic and semantic evidence for [NAME] as a feature. The syntactic evidence is found in languages like Modern Greek and Seri, where proper names normally require an overt determiner but appear bare in certain contexts. 
(7) Modern Greek (Anderson 2007: 180)

a. Aftos ine o Vasilis.

this is the Basil

'This is Basil.'

b. Onomazete Vasilis.

call.PASS.3SG Basil

'He is called Basil.'

c. Vasili!

Basil

'Basil!'

(8) Seri (Marlett 2008: 49-78)

a. Hipíix Juan quih haa

ha.

this.one Juan the one.that.is DECL

'This is Juan.'

b. Pancho mpah.

Pancho call.PASS.3SG

'He is called Pancho.'

c. Pedro, ¿áz intáho?

Pedro what see.PST.2SG

'Pedro, what did you see?'

The determiner is only required with proper names when they occur in argument position $(7 a, 8 a)$, not in naming constructions $(7 b, 8 b)$ or as vocatives $(7 c, 8 c)$. Crucially, they are still interpreted as names in non-argument positions. A similar phenomenon occurs in English, where proper names that are lexically specified to include the definite article (the Bronx, the Hague) do not require it when used as modifiers (Borer 2005; Ghomeshi \& Massam 2009).

(9) a. He is a Bronx-lover.

b. Hague and non-Hague countries

The data in (7)-(9) indicate that whatever makes a name a name cannot be related to D since the interpretation of a name is unaffected by the presence or absence of a determiner. For this reason, Ghomeshi \& Massam (2009) propose a [NAME] feature on N.

Regarding the semantic evidence for [NAME], Thomsen (1997) departs from the view that proper names denote individuals, while common nouns denote sets, arguing instead that both denote sets. However, these sets are identified differently. Proper names are binary predicates, or predicates of type $\langle e,\langle e, t\rangle\rangle$, that denote sets of entities that share a name. In contrast, common nouns are unary predicates, or predicates of type $\langle e, t\rangle$, that denote sets of entities that share properties. Consider the minimal pair the Danish Bank and the Danish bank, which Thomsen (1997: 101) assigns the following semantic values.

$$
\begin{aligned}
& \text { a. } \llbracket \text { the Danish Bank } \rrbracket=\text { def. sing. }+\{x \text { : is-named }(x, \text { Danish Bank })\} \\
& \text { b. } \llbracket \text { the Danish bank } \rrbracket=\text { def. sing. }+\{x: \operatorname{danish}(x) \& \operatorname{bank}(x)\}
\end{aligned}
$$

In (10a), the semantic value of the proper name the Danish Bank is a unique member of the set of entities that are named Danish Bank. In (10b), the semantic value of the common noun the Danish bank is a unique member of the intersection of two sets, one of entities that are Danish 
and the other of entities that are banks. Matushansky (2006: 288) agrees that proper names are binary predicates and posits that the naming convention $R$ saturates one of their arguments.

$$
\llbracket \text { Alice } \rrbracket=\lambda x \in D_{e} \cdot \lambda R . x \text { is a referent of /ælıs/ by virtue of the naming convention } R
$$

As a working definition, I suggest that what [NAME] encodes as a feature is membership in a set that is identified by a shared name, not by shared properties.

Adopting a Distributed Morphology approach, I propose that names and nouns result from different categorizing heads (Embick \& Marantz 2008). Names consist of roots that are categorized by $n_{\text {[NAME] }}(12 \mathrm{a})$, while nouns consist of roots that are categorized by $n(12 \mathrm{~b}) .^{3}$

a.

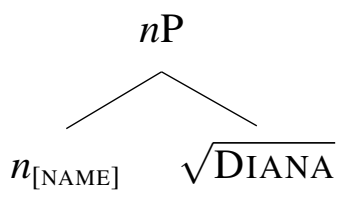

b.

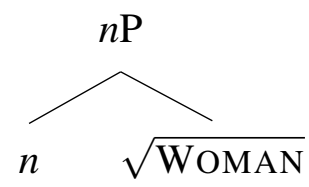

This analysis achieves two desiderata: 1) classifying names as a nominal category, and 2) formally distinguishing names from nouns.

3.1. Proper names And Regularization. As Kim et al. (1994), Marcus et al. (1995), and Pinker $(1998,1999)$ observe, proper names that are derived from irregular nouns regularize.

(13) English (Kim et al. 1994: 184)

a. We're having Julia Child and her husband over for dinner. You know, the \{Childs/ *Children $\}$ are really great cooks.

b. I keep telling my father to buy a Mercedes, but he insists that with that kind of money he could buy several Renault $\{$ Elfs/*Elves $\}$.

(14) German (Marcus et al. 1995: 229-230)

a. Wiese 'meadow' $\rightarrow$ Wiesen 'meadows'

Wiese (surname) $\rightarrow$ Wieses

b. Kadett 'cadet' $\rightarrow$ Kadetten 'cadets'

Kadett (car model) $\rightarrow$ Kadetts

(15) Hungarian (Pinker 1999: 233)

a. madár 'bird' $\rightarrow$ madarak 'birds'

Madár (surname) $\rightarrow$ Madárok

b. ló 'horse' $\rightarrow$ lovak 'horses'

Ló (surname) $\rightarrow$ Lók

Their account of regularization consists of two arguments. First, proper names are semantically incompatible with the notion of plurality, so they must be converted into nouns before they can be pluralized. Second, the resulting nouns are exocentric (i.e., someone named "Child" is not a type of child) and, as a result, cannot access any idiosyncratic information stored in lexical

${ }^{3}$ I concur with Acquaviva (2009) and Harley (2014) that roots are indices before insertion but use $\sqrt{\text { DIANA }}$ and $\sqrt{\text { WOMAN }}$ for ease of presentation. 
entries. However, this analysis ignores derived proper names that are hyponyms of the source noun (e.g., Mickey Mouse, who is a type of mouse). Even if the proper name Mickey Mouse were converted into a noun so that it could be used to refer to a collectivity of the character, it would still be a hyponym. In short, there appear to be endocentric proper names as well as exocentric ones, a phenomenon that has yet to be investigated in the literature.

Before addressing the behavior of endocentric proper names, a point of clarification is in order. English capitalization does not always reflect the morphosyntactic definition of proper names, or "names that appear as bare arguments". Since none of the examples in (2) fits this description (e.g., *Big Bad Wolf blew the house down), their irregular plural forms are unsurprising. Syntactically, such "names" are identical to the big bad wolf and the golden goose and will not be discussed further.

3.2. Endocentric PROPER nAmes. Proper names like Mickey Mouse, Superman, and Wonder Woman are the exception, not the rule (Jambrović 2020). In general, there are no readings in which a proper name that is derived from a noun can be considered to be a type of that noun, but proper name compounds with an animate head may give rise to semantic ambiguities depending on their usage. For instance, Wonder Woman is named "Wonder Woman" but is also a type of woman. In this way, both of Thomsen's (1997) semantic values are possible.

$$
\begin{array}{ll}
\text { a. } & \llbracket \text { Wonder Woman } \rrbracket=\text { def. sing. }+\{x: \operatorname{is-named}(x, \text { Wonder Woman })\} \\
\text { b. } & \llbracket \text { Wonder Woman } \rrbracket=\text { def. sing. }+\{x: \operatorname{wonder}(x) \& \operatorname{woman}(x)\}
\end{array}
$$

In the syntax, this ambiguity can be captured by the use of $n$ as the nominalizer for nouns and $n_{\text {[NAME }]}$ as the nominalizer for names.

The regularization that is observed with names is unsurprising if one accepts Kim et al.'s (1994) position, shared by Marcus et al. (1995) and Pinker (1998, 1999), that names cannot be directly pluralized. In fact, Ghomeshi \& Massam (2020) make a similar claim, suggesting that names receive a singular interpretation by default, not because of a Num projection valued as [SG]. Lastly, other researchers have argued that $n \mathrm{P}$ is the domain of lexical number, while NumP is the domain of individuation (Acquaviva 2004; Kramer 2016; Smith 2016).

Assuming that names must be converted into nouns before they can take plural morphology, this process disrupts the locality conditions necessary for contextual allomorphy. Compare the structure of Childs in (17a) with that of children in (17b).

a.

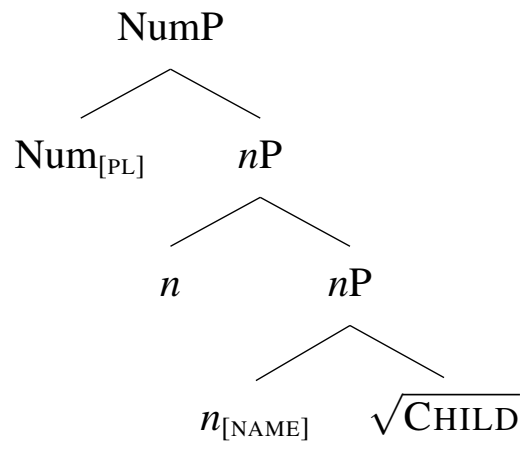

b.

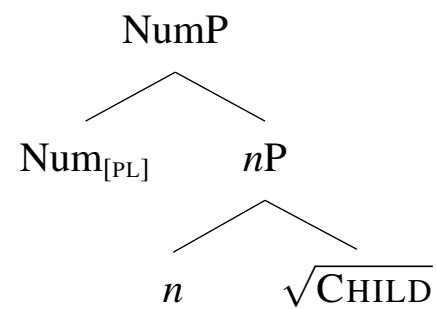

According to Embick (2010), Num can only access the root through a single cyclic node, but there are two in (17a); recall that Num cannot directly merge with $n_{\text {[NAME] }} \mathrm{P}$, which is inter- 
preted as singular by default. ${ }^{4}$ That is, for a name to combine with anything other than a proper determiner, it must first be converted into a noun. It can then appear with overt articles $(18 \mathrm{a}, \mathrm{b})$ and quantifiers (18c) (Burge 1973: 429).

(18) a. An Alfred Russell joined the club today.

b. The Alfred who joined the club today was a baboon.

c. Some Alfreds are crazy; some are sane.

Finally, it is worth emphasizing that a $n_{[\mathrm{NAME}]} \mathrm{P}$ layer is essential for the correct interpretation of the names in (18): in each case, Alfred denotes the set of entities named Alfred, not a set of entities identified by a set of properties. ${ }^{5}$ However, the name is not countable until it has been recategorized as a noun.

I now return to the exceptional proper names at the beginning of this section, which offer the rare opportunity to bypass the more complex structure in (17a). For example, if Wonder Woman were to create an army of clones, there would be a plurality of individuals belonging to 1) the set of entities named "Wonder Woman", and 2) the set of entities identified by the properties associated with Wonder Woman. ${ }^{6}$ Under the latter reading, Wonder Woman is a noun (i.e., wonder woman) and can merge directly with Num, resulting in contextual allomorphy (Wonder Women/wonder women). On the other hand, if a particular entity is named after a character but is not itself an instance of that character, as in the following data from Kim et al. 1994: 184, the irregular plural form is ungrammatical.

a. I'm sick of all the Mickey $\{$ Mouses/*Mice $\}$ that have been running this country for the past 12 years.

b. Movie sequels are really getting out hand; there are two $\{$ Batmans $/ *$ Batmen $\}$ and who knows how many $\{$ Supermans $/ *$ Supermen $\}$ there are.

This outcome is expected given that the derived nouns in (19) contain a $n_{[\mathrm{NAME}]} \mathrm{P}$ layer, which prevents contextual allomorphy.

To conclude, variable inflection can be linked to the unusual possibility of two nominalizers in semantically ambiguous contexts: $n$ and $n_{\text {[NAME] }}$.

3.3. COMMON NAMES. If regularization is due to a $n_{\text {[NAME] }} \mathrm{P}$ layer in the structure, then nouns that are "named" after other nouns should regularize as well. Based on the entries in (20) from the American Heritage Dictionary, this prediction seems to be borne out.

(20) a. foot (plural foots): sediment that forms during the refining of oil and other liquids

b. goose (plural gooses): a tailor's pressing iron with a long curved handle

c. louse (plural louses): a mean or despicable person

These definitions suggest that these are not cases of homophony since there is a clear semantic connection between the source noun and the derived name. Nor are they instances of metaphorical extension, which preserve irregular plural forms. For example, the original usage of foot as a measurement was not a name but rather a metaphorical extension of the body part; to say

\footnotetext{
4 This account is also compatible with the argument that irregular plural morphology is realized on $n$. As Embick (2010) argues, non-cyclic heads such as Num can access the root through a single cyclic head. What is not possible is for a higher cyclic head to access the root through a lower one, as in $\left[n\left[n_{[\mathrm{NAME}]} \mathrm{P}[\sqrt{ }]\right]\right]$.

${ }^{5}$ Excluding, of course, the property of being named "Alfred".

${ }^{6}$ The second option is not available with surnames since they do not identify any properties.
} 
"my house is fifty feet from the road" meant the literal distance of fifty human feet. In contrast, a tailor's goose has never been interpreted as a literal goose, meaning that the term was coined as a name and, as a result, regularizes in the plural.

The previous discussion sheds light on the variable inflection of mouse in the computing sense, which is not a counterexample despite the fact that it has two recognized plural forms, mice and mouses. Whereas foot (as a measurement) is a metaphorical extension and goose (as an iron) is not, mouse (as computer hardware) is somewhere in between. Its design and motion are vaguely reminiscent of how a mouse looks and moves, yet it is not a literal mouse, hence speakers' uncertainty when forming the plural.

The common names in (20) have the same structure as Childs in (17a). As before, a second cyclical head between Num and the root interrupts contextual allomorphy, accounting for the regularized plural forms.

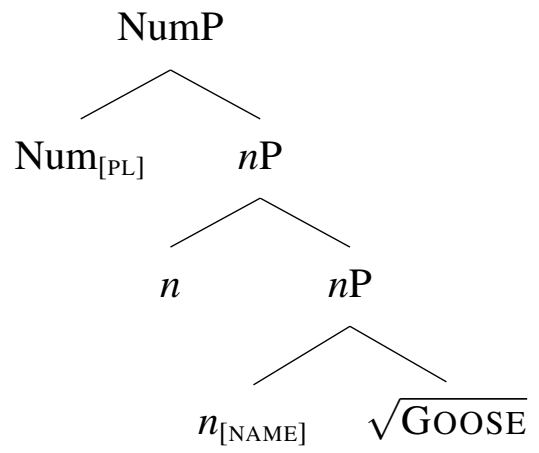

In addition, this structure drives the correct reading: goose (as an iron) denotes a set of entities that have properties in common, but these are not necessarily the properties of goose (as a bird), which has a simpler structure.

3.4. SumMARY. This section explored a number of morphosyntactic phenomena that can be captured by the presence or absence of a $n_{[\mathrm{NAME}]} \mathrm{P}$ layer in the structure. The predictions of this analysis are formalized in (22).

(22) a. If a nominal element regularizes in its inflection, it contains a $n_{\text {[NAME] }} \mathrm{P}$ layer.

b. If variable inflection of a nominal element is possible, the entity in question is semantically ambiguous; it can be interpreted as either a name or a hyponym.

c. Metaphorical extension preserves irregular morphology; saying that one entity is another is structurally simpler than naming one entity after another.

4. A theory of [PROPER]. In many languages, including English and Spanish, names readily appear as bare arguments (23), unlike singular count nouns (24).

(23) a. Donald awaits trial.

b. Callas murió joven.

Callas die.PST.3SG young

'Callas died young.'

(24) a. *Dog plays in the yard.

b. *Gato duerme en la casa.

cat sleep.3SG in the house 
Still, some names may optionally occur with a determiner (25), and others are even lexically specified to include one (26), so the system needs to be flexible (Ghomeshi \& Massam 2009).

(25) a. (The) Donald went bankrupt.

b. (La) Callas definió una generación.

the Callas define.PST.3SG a generation

'(The) Callas defined a generation.'

(26) a. the Bronx, the Hague, the Who

b. the Atlantic (Ocean), the Mediterranean (Sea), the (River) Thames

In light of these facts, there must be a way to differentiate names that can appear bare from those that cannot. The optionality of the determiner in (25) reveals that [NAME] cannot be relevant factor, and an account based on N-to-D movement cannot easily be extended to English (see section 4 of Longobardi 1994).

Ghomeshi \& Massam's (2009: 75) solution is a [PROPER] feature on D to distinguish the null proper determiner in (27a) from the overt definite one in (27b).

$$
\begin{array}{ll}
\text { a. } & {[\mathrm{DEF}, \mathrm{SG}, \mathrm{PROPER}] \leftrightarrow \varnothing} \\
\text { b. } & {[\mathrm{DEF}] \leftrightarrow \text { the }}
\end{array}
$$

The system now has the desired flexibility. Bare proper names have the structure in (28a), while proper names that occur with an overt determiner have the structure in (28b).

a.

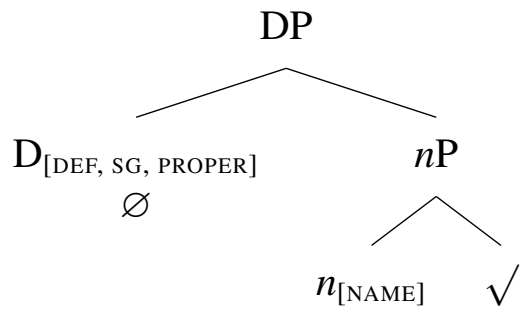

b.

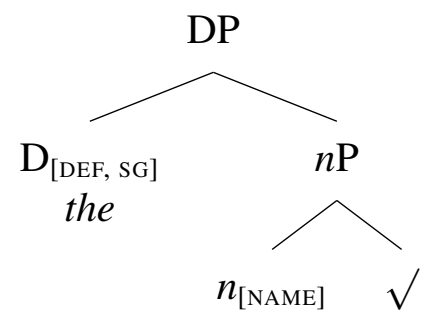

However, what does [PROPER] encode as a feature? Unlike the semantic contribution of [DEF], [SG], and [NAME], that of [PROPER] is not yet established in the literature. For instance, a [PROPER] feature does not make a DP "more" definite.
a. He is Picasso.
b. He is the Picasso.

Both Picasso and the Picasso denote a unique member of the set of entities named Picasso; the only difference between the sentences in (29) is that the use of the definite article has a pragmatic effect, indicating that the unique member in question is the famous one. The sole purpose of the proper determiner seems to be to license names as bare arguments.

Having arrived at this working definition of [PROPER], it is an empirical question whether it can license singular count nouns as well, a possibility that Ghomeshi \& Massam (2009) discard on theoretical grounds. Before presenting data in section 4.2 that supports the notion of proper nouns as a distinct structural configuration, I rule out some of the other morphosyntactic processes that [PROPER] is thought to participate in, narrowing down its function to null determiner spell-out. 
4.1. NARROWING DOWN [PROPER]. Ghomeshi \& Massam (2009: 88) observe that demonstratives in Persian can co-occur with the definite determiner (30a) but not with the proper determiner (30b).
a. un sæg-e xabid.
that dog-DEF.SG slept.3SG
'That dog slept.'
b. *un kian xabid.
that Kian slept.3SG
'That Kian slept.'

Suggesting that demonstratives in Persian are sensitive to [PROPER], their argument assumes that DemP is generated higher than DP, a controversial stance. Using data from Greek and Romance, Alexiadou et al. (2007) and Brugè (2002) claim that demonstratives are generated below DP universally, a position that casts doubt on [PROPER] as the source of the ungrammaticality in (30b).

A related issue is the personal, or proprial, article in Catalan, which only occurs with proper names $(31 \mathrm{c}, \mathrm{d})$.
a. el gos the.M dog
b. la vaca the.F cow
c. en Pere the.M Pere
d. na Maria the.F Maria

Ghomeshi \& Massam (2009) describe the Catalan personal article as a definite determiner, yet Bernstein et al. (2019: 93) show that it merges below D in the same position as the Spanish honorific don/doña, which derive from Latin dominus 'master'.
a. el propi en Pere the same ART Pere 'Pere himself'
b. el mismo don Luis the same Mr Luis 'Mr Luis himself'

Bernstein et al. (2019) propose that a [HUMAN] feature is the reason that the personal article is only compatible with names in Catalan. This same feature has been argued by Alexiadou (2004) to be relevant for gender assignment in the case of Harris's (1991) "mated" pairs (e.g., amigo/amiga 'friend.M/friend.F'), which is established via identification with a human referent. ${ }^{7}$ Both of these perspectives are compatible with the current proposal: in these languages, $n$ and $n_{\text {[NAME] }}$ may optionally contain a [HUMAN] feature, though further investigation may find that $[\mathrm{NAME}]$ alone captures the data.

\footnotetext{
${ }^{7}$ As opposed to non-human, non-animate nouns, which are inherently specified for gender.
} 
4.2. PROPER NOUNS AND THE PARADIGM GAP. The distinct inflectional behavior of names and nouns offers a useful diagnostic for determining whether a bare form is a proper name or a proper noun. For example, Ghomeshi \& Massam (2009: 80-81) classify the following usages of Mole and Kiu 'Plover' as proper names.

a. "...that suddenly reached Mole in the darkness, ..."

b. Pehe a Kiu ka ...

said ABS.P kiu if

'Kiu said "if ...",

However, the label "proper name" here is based on the stipulation that the selectional properties of the proper determiner prevent it from merging with a common noun.

An empirical approach to the question is to replace mole with an irregular noun such as mouse or goose and consider how it would pluralize in this context. If, in the world of the story, the names of the characters were simply the type of animal that they were, and there were two characters named "Mouse", they would be referred to as the Mice, not *the Mouses. The use of irregular morphology with Mouse suggests that Mole in (33a) is a proper noun, not a proper name. One could regard this phenomenon as another instance of metaphorical extension, as discussed in section 3.3. In other words, it is not the case that the character is named Mole, but rather it simply is a mole.

Importantly, while [PROPER] is a feature on bare singular usages of names, it is not the source of their singular interpretation; $n_{\text {[NAME] }}$ is. The lack of plural proper names and proper nouns is evidenced by the need for an overt determiner in plural contexts: *(the) Childs live next door, *(the) Mice are the heroes of the story, and so forth. Given that the proper determiner is null in English, a [PL] feature on D is mutually exclusive with [PROPER].

4.3. FURTHER EVIDENCE OF PROPER NOUNS. There is no a priori reason to assume that the proper determiner cannot license singular count nouns in addition to names. The data in this section indicate that proper nouns are, in fact, quite common in English.

As Stvan (2007: 177-178) observes, two tests reveal cases of bare singular count nouns that are interpreted as definite, just as bare proper names are: 1) identifiability to the hearer, and 2) anaphora.

a. My dad was in town the weekend before my birthday.

Identifiability to hearer: my town/your town/my father's town

Anaphora: [I just moved to [a new town $]_{\mathrm{i}}$ last year.] My dad was in [town $]_{\mathrm{i}}$ the weekend before my birthday.

b. I work at home, and I have found that this arrangement has a tremendous potential for personal growth.

Identifiability to hearer: my home

Anaphora: [I have both an office and [a private residence $\left.]_{i}.\right]$ I work at [home $]_{i}$.

These definite usages of bare singular count nouns also occur as subjects (35a) and direct objects (35b), not only as prepositional objects (Stvan 2009: 322-323).

(35) a. [Someone from your] school called and said that classes were cancelled for today.

b. They-whoever they is-think I've left town and I want to keep it that way.

${ }^{8}$ Grahame 1961, Loeb 1926 
Lastly, there are corpus examples of bare singular count nouns that are capitalized as if they were proper names (Stvan 2007: 179).

(36) a. This was the news with which Miss Hillyard had had to face Miss Lydgate when the latter returned to College immediately after breakfast on the Monday. ${ }^{9}$

b. If the installation of in-street pedestrian crossing signs is approved by the Council tonight, we will use these guidelines to evaluate conditions at other unsignalized crosswalks in Town.

In (36a), College refers to Shrewsbury College, a fictional part of Oxford University, not to a place named "College". Likewise, in (36b), Town refers to Chapel Hill, North Carolina, not to a place named "Town".

The proper nouns in (34)-(36) have much in common with proper names: they are definite, singular, and have a null determiner, suggesting that they are also licensed as bare arguments by $\mathrm{D}_{\text {[DEF, SG, PROPER] }}$. What distinguishes proper nouns from proper names is the absence of a $n_{[\mathrm{NAME}]} \mathrm{P}$ layer, hence their failure to regularize in plural contexts.

4.4. Summary. This section investigated the possibility of the proper determiner selecting common nouns as well as names, which was previously ruled out on theoretical grounds. There are two types of evidence in English that undermine this claim. First, when the "name" of an entity coincides with the type of entity that it is (e.g., Mouse, Goose), this nominal element inflects as if it were a noun (the Mice, the Geese), not a name (the Mouses, the Gooses), ruling out a $n_{\text {[NAME] }}$ layer in the structure. Second, there are definite usages of bare singular count nouns that have the same distribution as proper names, key evidence in favor of the proper determiner merging with common nouns.

5. Conclusion. Previous research establishes the need for a dual-feature account of proper names. However, the independent morphosyntactic effects of these features-[PROPER] on D and [NAME] on $n$-have not been adequately considered.

As a feature on $n$, [NAME] encodes membership in a set of entities that are identified by a shared name rather than by shared properties. At least two cases of inflectional regularization can be captured with $n_{\text {[NAME] }}$ as the initial categorizing head of a root: proper names and nouns that are "named" after other nouns. Moreover, the data in this paper support a distinction between naming and metaphorical extension: naming results in regularization, while metaphorical extension does not.

It remains to be determined whether [PROPER] has a function beyond licensing bare singular arguments, but what is now clear is that the proper determiner is not limited to selecting names. The combination of a proper determiner and a common noun has been previously rejected for theoretical reasons, but there are definite usages of bare singular count nouns in English that call this stipulation into question. Finally, this paper provides a formal analysis of proper nouns that explains why they have the same distribution of proper names but do not regularize in their inflection: without a $n_{[\mathrm{NAME}]} \mathrm{P}$ layer, they are unique members of sets identified by common properties, not by a common name.

${ }^{9}$ Sayers 1935 


\section{References}

Acquaviva, Paolo. 2004. Constraining inherent inflection: Number and nominal aspect. Folia Linguistica 38(3/4). 333-354. https://doi.org/10.1515/flin.2004.38.3-4.333.

Acquaviva, Paolo. 2009. Roots and lexicality in Distributed Morphology. In Alexandra Galani, Daniel Redinger \& Norman Yeo (eds.), York-Essex Morphology Meeting 5, 1-21. York: University of York.

Adger, David. 2003. Core syntax: A Minimalist approach. Oxford: Oxford University Press. Alexiadou, Artemis. 2004. Inflection class, gender, and DP internal structure. In Gereon Müller, Lutz Gunkel \& Gisela Zifonun (eds.), Explorations in nominal inflection, 21-49. Berlin: Mouton de Gruyter. https://doi.org/10.1515/9783110197501.21.

Alexiadou, Artemis, Liliane Haegeman \& Melita Stavrou. 2007. Noun phrase in the generative perspective. Berlin: Mouton de Gruyter. https://doi.org/10.1515/9783110207491.

Anderson, John M. 2007. The grammar of names. Oxford: Oxford University Press. https: //doi.org/10.1093/acprof:oso/9780199297412.001.0001.

Bernstein, Judy, Francisco Ordóñez \& Francesc Roca. 2019. On the emergence of personal articles in the history of Catalan. In Miriam Bouzouita, Anne Breitbarth, Lieven Danckaert, \& Elisabeth Witzenhausen (eds.), Cycles in language change, 88-108. Oxford: Oxford University Press. https://doi.org/10.1093/oso/9780198824961.003.0006.

Borer, Hagit. 2005. Structuring sense, volume I: In name only. Oxford: Oxford University Press. https://doi.org/10.1093/acprof:oso/9780199263905.001.0001.

Brugè, Laura. 2002. The position of demonstratives in the extended nominal projection. In Guglielmo Cinque (ed.), Functional structure in DP and IP: The cartography of syntactic structures, volume 1, 15-53. Oxford: Oxford University Press.

Burge, Tyler. 1973. Reference and proper names. The Journal of Philosophy 70(14). 425-439. https://doi.org/10.2307/2025107.

Camacho, José. 2019. Un tal Ernestico/a certain Ernestico: On the structure of proper names. Glossa: A Journal of General Linguistics 4(1). 44.1-23. https://doi.org/10.5334/gjgl.774.

De Clercq, Karen. 2008. Proper names used as common nouns in Belgian Dutch and German. In Marjo van Koppen \& Bert Botma (eds.), Linguistics in the Netherlands 2008, 63-74. Amsterdam: John Benjamins Publishing Company. https://doi.org/10.1075/avt.25.09dec.

Embick, David. 2010. Localism versus globalism in morphology and phonology. Cambridge, MA: The MIT Press. https://doi.org/10.7551/mitpress/9780262014229.001.0001.

Embick, David \& Alec Marantz. 2008. Architecture and blocking. Linguistic Inquiry 39(1). 1-53. https://doi.org/10.1162/ling.2008.39.1.1.

Ghomeshi, Jila \& Diane Massam. 2009. The proper D connection. In Jila Ghomeshi, Ileana Paul \& Martina Wiltschko (eds.), Determiners: Universals and variation, 67-96. Amsterdam: John Benjamins Publishing Company. https://doi.org/10.1075/la.147.02gho.

Ghomeshi, Jila \& Diane Massam. 2020. Number is different in nominal and pronominal phrases. Linguistic Inquiry 51(3). 597-610. https://doi.org/10.1162/ling_a_00350.

Grahame, Kenneth. 1961. The wind in the willows. New York, NY: Charles Scribner's Sons.

Harley, Heidi. 2014. On the identity of roots. Theoretical Linguistics 40(3/4). 225-276. https: //doi.org/10.1515/tl-2014-0010.

Harris, James W. 1991. The exponence of gender in Spanish. Linguistic Inquiry 22(1). 27-62. 
Jambrović, Samuel. 2020. Derived nouns and inflectional variability: A case for distinct nominalizers. In Angélica Hernández \& M. Emma Butterworth (eds.), Proceedings of the 2020 annual conference of the Canadian Linguistic Association, 1-14.

Kim, John J., Gary F. Marcus, Steven Pinker, Michelle Hollander \& Marie Coppola. 1994. Sensitivity of children's inflection to grammatical structure. Journal of Child Language 21(1). 173-209. https://doi.org/10.1017/s0305000900008710.

Kramer, Ruth. 2016. A split analysis of plurality: Number in Amharic. Linguistic Inquiry 47(3). 527-559. https://doi.org/10.1162/ling_a_00220.

Loeb, Edwin M. 1926. History and traditions of Niue. Honolulu, HI: Bernice P. Bishop Museum.

Longobardi, Giuseppe. 1994. Reference and proper names: A theory of N-movement in syntax and Logical Form. Linguistic Inquiry 25(4). 609-665.

Longobardi, Giuseppe. 2005. Towards a unified grammar of reference. Zeitschrift für Sprachwissenschaft 24. 5-44. https://doi.org/10.1515/zfsw.2005.24.1.5.

Marcus, Gary F., Ursula Brinkmann, Harald Clahsen, Richard Wiese \& Steven Pinker. 1995. German inflection: The exception that proves the rule. Cognitive Psychology 29(3). 189256. https://doi.org/10.1006/cogp.1995.1015.

Marlett, Stephen A. 2008. The form and use of names in Seri. International Journal of American Linguistics 74(1). 47-81. https://doi.org/10.1086/529463.

Matushansky, Ora. 2006. Why Rose is the Rose: On the use of definite articles in proper names. In Olivier Bonami \& Patricia Cabredo Hofherr (eds.), Empirical issues in formal syntax and semantics 6: Papers from CSSP 2005, 285-307. Paris: Colloque de Syntaxe et Sémantique à Paris.

Pinker, Steven. 1998. Words and rules. Lingua 106(1/4). 219-242. https://doi.org/10.1016/ S0024-3841(98)00035-7.

Pinker, Steven. 1999. Words and rules: The ingredients of language. New York, NY: Harper Perennial.

Sayers, Dorothy L. 1935. Gaudy night. London: Gollancz.

Smith, Peter W. 2016. Count-mass nouns, inherent number and the unmasking of an impostor. In Ross Burkholder, Carlos Cisneros, Emily R. Coppess, Julian Grove, Emily A. Hanink, Hilary McMahan, Cherry Meyer, Natalia Pavlou, Özge Sarıgül, Adam Roth Singerman \& Anqi Zhang (eds.), Proceedings of the Fiftieth Annual Meeting of the Chicago Linguistic Society, 427-438.

Stvan, Laurel Smith. 2007. The functional range of bare singular count nouns in English. In Elisabeth Stark, Elisabeth Leiss \& Werner Abraham (eds.), Nominal determination: Typology, context constraints, and historical emergence, 171-187. Amsterdam: John Benjamins Publishing Company. https://doi.org/10.1075/slcs.89.10stv.

Stvan, Laurel Smith. 2009. Semantic incorporation as an account for some bare singular count noun uses in English. Lingua 119(2). 314-333. https://doi.org/10.1016/j.lingua.2007.10. 017.

Thomsen, Hanne Erdman. 1997. On the proper treatment of proper names. Nordic Journal of Linguistics 20(1). 91-110. https://doi.org/10.1017/S0332586500004029. 